\title{
Do bonding and bridging social capital have differential effects on self-rated health? A community based study in Japan
}

\section{Citation}

Iwase, Toshihide, Etsuji Suzuki, Takeo Fujiwara, Soshi Takao, Hiroyuki Doi, and Ichiro Kawachi. 2010. "Do Bonding and Bridging Social Capital Have Differential Effects on Self-Rated Health? A Community Based Study in Japan." Journal of Epidemiology and Community Health 66 (6): 55762. https://doi.org/10.1136/jech.2010.115592.

\section{Permanent link}

http://nrs.harvard.edu/urn-3:HUL.InstRepos:41288143

\section{Terms of Use}

This article was downloaded from Harvard University's DASH repository, WARNING: This file should NOT have been available for downloading from Harvard University's DASH repository.

\section{Share Your Story}

The Harvard community has made this article openly available.

Please share how this access benefits you. Submit a story.

Accessibility 


\title{
Do bonding and bridging social capital have differential effects on self-rated health? A community based study in Japan
}

\author{
Toshihide Iwase, ${ }^{1}$ Etsuji Suzuki, ${ }^{1}$ Takeo Fujiwara, ${ }^{2}$ Soshi Takao, ${ }^{1}$ Hiroyuki Doi, \\ Ichiro Kawachi ${ }^{3}$
}

- An additional appendix is published online only. To view this file please visit the journal online (http://jech.bmi.com/ content $/ 66 / 6 . t o c)$

${ }^{1}$ Department of Epidemiology, Okayama University Graduate School of Medicine, Dentistry and Pharmaceutical Sciences, Okayama, Japan

${ }^{2}$ Section of Behavioral Science, Department of Health Promotion, National Institute of Public Health, Saitama, Japan ${ }^{3}$ Department of Society, Human Development and Health, Harvard School of Public Health, Boston, Massachusetts, USA

\section{Correspondence to}

Toshihide Iwase, Department of Epidemiology, Okayama University Graduate School of Medicine, Dentistry and Pharmaceutical Sciences, 2-5-1 Shikata-cho, Kita-ku, Okayama 700-8558, Japan

satane13@gmail.com

Accepted 13 November 2010 Published Online First 16 December 2010

\begin{abstract}
Background Few studies have examined the potential difference in the relationship between bonding versus bridging social capital and health outcomes. We sought to examine the association between these different types of social capital and self-rated health in a population-based study.
\end{abstract}

Methods In February 2009, 4000 residents of Okayama City (aged 20-80 y) were randomly selected for a survey on social capital and health. The survey asked about participation in six different types of associations: Parents and Teachers Association, sports clubs, alumni associations, political campaign clubs, citizen's groups and community associations. We distinguished between bonding and bridging social capital by asking participants about their perceived homogeneity (with respect to gender, age and occupation) of the groups they belonged to. ORs and $95 \% \mathrm{Cls}$ for poor health were calculated.

Results Bridging social capital (ie, participation in groups involving people from a diversity of backgrounds) was inversely associated with poor health in both sexes and women appeared to benefit more than men. Compared to those who reported zero participation, high bridging social capital was associated with a reduced odds of poor health (OR $0.25,95 \% \mathrm{Cl} 0.11$ to 0.55 ) in women after controlling for demographic variables, socioeconomic status, smoking habit and overweight. By contrast, bonding social capital was not consistently associated with better health in either gender.

Conclusions The present study suggests that bonding and bridging social capital have differential associations with health and that the two forms of social capital need to be distinguished in considering interventions to promote health.

\section{INTRODUCTION}

Social capital has been conceptualised and measured according to two different approaches. ${ }^{1}$ Within sociology and economics, researchers tend to treat social capital as an individual-level attribute-that is, as resources accruing to individuals through their connections to durable social networks. By contrast, much of the research in public health has treated social capital as a grouplevel attribute. For example, social cohesion is regarded as a property of the group not of the individuals who belong to the group. In turn, social cohesion is theorised to promote health by enforcing healthy norms, sanctioning deviant behaviour and facilitating collective action as well as the diffusion of innovations. ${ }^{1-3}$
A number of investigations have sought to examine the association between social capital (measured as social cohesion) and various health outcomes. ${ }^{4-11}$ However, the findings across these studies have not been consistent with several studies reporting null findings. ${ }^{12-14}$ Several alternative explanations have been put forwards to account for the heterogeneous findings across studies, including (a) the fact that the studies were conducted at different levels of spatial aggregation so that different mechanisms of action may be involved at each level, (b) the studies used inconsistent measures to operationalise the construct of social capital, (c) studies conducted in more egalitarian contexts tend to report null results, suggesting some type of constrained variability in the 'exposure' variable, ${ }^{15}$ and (d) the extent to which residual confounding is handled varies substantially between studies.

One shortcoming of the empirical social capital literature that has been repeatedly cited is the failure to distinguish between the effects of bonding versus bridging social capital. ${ }^{1}{ }^{16-18}$ Bonding social capital refers to networks of dense ties between members of a group who are similar to each other with respect to social class, race/ ethnicity and other forms of social status, while bridging social capital refers to social connections that span across such lines of status. In addition, linking social capital has been used to refer to connections between individuals and groups with larger social institutions. ${ }^{1}{ }^{17}$ The theoretical importance of distinguishing between these types of capital is underscored by the few studies to date, which suggested that they have different associations with health outcomes. To our knowledge, only three studies have explicitly distinguished between bonding and bridging social capital and their relationships to health outcomes. Mitchell and LaGory ${ }^{19}$ examined the association of bonding versus bridging social capital in a disadvantaged, minority, community in Birmingham, USA. They found that whereas bridging capital was associated with lower levels of mental distress, bonding capital had the opposite effect-that is, poor minority women in their sample with strong ties to others in the community who were just like them (with respect to racial and socioeconomic status) were more likely to report mental distress. Beaudoin $^{20}$ defined bonding and bridging social capital based on the degree of similarity with neighbours in the dimension of race/ethnicity and reported that bonding social capital had a salutary association 
with self-rated health, as well as an inverse association with stress, whereas bridging social capital was not associated with self-rated health or stress. In a multilevel study, Kim et al ${ }^{21}$ reported that both individual level and community level bonding social capital (defined on the basis of gender, race/ethnicity and education) were associated with better self-rated health, whereas no clear associations were found for community level bridging social capital.

There are three important gaps in the literature that remain to be addressed. First, previous studies based in the USA ${ }^{2021}$ have defined bonding and bridging social capital on the basis of race/ ethnicity, which makes sense from the historical viewpoint of racial segregation. However, if social capital is to have use in other societal contexts, the bonding and bridging cleavage is likely to fall across other dimensions. For example, in Japanese residents over $98 \%$ are identified as 'Japanese" 22 and ethnicity is virtually indistinguishable based on external appearance. Undeniably, discrimination occurs in Japanese society against foreigners. Nevertheless, the more visible social cleavages tend to fall along the dimensions of social class and gender. Second, the bulk of past studies have been conducted in Western countries, while few studies have been reported in Asian countries. Indeed, the possible differential effects of bonding and bridging social capital on population health may be highly contingent on the social and historical context. ${ }^{12} 23$ Third, the significance of distinguishing between bonding and bridging social capital has been mainly discussed in the context of socioeconomic disadvantage - that is, bridging capital is cited as a mechanism for disadvantaged residents to access various resources for success. $^{24-26}$ To advance the understanding of bonding and bridging social capital, studies are needed in a variety of social contexts.

Therefore, we investigated the association between bonding and bridging social capital and self-rated health using a population-based sample in Japan.

\section{METHODS}

\section{Participants}

Data were obtained from the Okayama Social Capital Study conducted by the City Government of Okayama, Japan. In February 2009, the City Government mailed a postal survey of 4000 randomly selected residents of that city. The survey used a clustered sampling approach to select 20 elementary school districts. Within each school district, 200 residents aged 20-80 years were selected using the Basic Resident Registration (residential records in Japan managed by the national and prefectural government) as the sampling frame. Of the 4000 mailed surveys, 61 were returned due to unknown address, deceased and for other reasons, and 2260 were returned (response rate: 56.5\%). The return of the questionnaire was viewed as implied consent. The investigators obtained data from the Okayama City Government stripped of all personal identifiers. The study protocol was reviewed and approved by the Institutional Review Board at the Harvard School of Public Health (protocol\#18977-101).

\section{Measures}

We consulted previous studies ${ }^{19} 2728$ and decided to derive the measure of social capital from survey item responses to participation in six different types of groups: Parents and Teachers Association (PTA), sports clubs, alumni associations, political campaign clubs, citizen's groups and community associations. We assessed whether each type of group represented bonding or bridging social capital by asking respondents to rate whether they were homogeneous or heterogeneous according to their social composition. ${ }^{1}{ }^{16-18} 27$ Specifically, the respondents were asked, 'Would you say that the composition of the group that you participate in is diverse or similar with respect to gender, age group, and occupational backgrounds?' Respondents who characterised their groups as 'similar' in background were classified being involved in bonding social capital, while those who characterised their groups 'diverse' were categorised as being involved in bridging social capital. Further, to check the 'dose-response' relationships between social capital and poor health, we categorised the number of groups that the respondents were active in according to four levels: none, one, two and three or more groups corresponding to 'none', 'low', 'middle' and 'high' social capital.

The dependent variable of self-rated health was assessed by the single questionnaire item: 'How would you rate your overall current state of health status: excellent, very good, good, fair or poor?' We created a dichotomous response variable (1=fair/poor; $0=$ excellent/very good/good). It has been shown that self-rated health is a strong and independent predictor of overall mortality in over two dozen prospective studies. ${ }^{29}$

In multivariable analyses, we adjusted for individual covariates, including demographic variables (age and living arrangement), educational attainment, smoking habit (never/past, current) and overweight in line with previous studies. ${ }^{3} 42021$ Living arrangement was categorised in two groups: living with children or parents and living without children and parents. Educational attainment was categorised as junior high school, high school, some college or college or more. We calculated body mass index from self-reported height and weight and defined 25 or higher (in $\mathrm{kg} / \mathrm{m}^{2}$ ) as being overweight.

\section{Statistical analyses}

The relationship between participation in bonding groups and participation in bridging groups was examined by Pearson's correlation coefficient. Then, sequential logistic regression analysis was used to examine the relationships of social capital and health status with subjects in the lowest social capital category (zero social participation) as the reference group. We conducted these analyses separately by sex. Model 1 included age (continuous), living arrangement, educational attainment, smoking habit and overweight. Model 2 added both bonding social capital and bridging social capital simultaneously. We also conducted stratified analyses by age groups (10-year categories) and educational attainment. Further, to explore the independent effects of bonding versus bridging social capital, the study population was also divided into four groups: people who have no social capital, people who have only bonding social capital, people who have only bridging social capital and people who have both bonding and bridging social capital.

ORs and 95\% CIs for poor health were calculated and $\mathrm{p}$ values were considered statistically significant at 0.05 (two-sided test). All analyses were conducted with STATA/SE version 10.1 (StataCorp) in 2010.

\section{RESULTS}

After excluding missing data on sex, age and health status, the study sample was comprised of 2155 people. The demographic and health characteristics of study sample are shown in table 1. According to the governmental report in $2009,{ }^{30}$ the mean age of the residents (aged 20-80 y) in Okayama city was 48.5 years and $51.6 \%$ of them were women. Further, due to census data in $2000,{ }^{31}$ the distribution of educational attainment among the residents (aged 20-79y) in Okayama prefecture was junior high 
Table 1 Demographic and health characteristics of the subjects

\begin{tabular}{lcc}
\hline Characteristics & Men (N=878) & Women (N=1277) \\
\hline Mean age, y (SD) & $53.2(15.9)$ & $52.5(16.6)$ \\
Living with children or parents, $\mathrm{n}(\%)$ & \\
$\quad$ No & $326(37.1)$ & $440(34.5)$ \\
Yes & $548(62.4)$ & $829(64.9)$ \\
$\quad$ Missing & $4(0.5)$ & $8(0.6)$ \\
Educational attainment, $\mathrm{n}(\%)$ & & \\
$\quad$ Junior high school & $108(12.3)$ & $116(9.1)$ \\
High school & $365(41.6)$ & $488(38.2)$ \\
Some college & $67(7.6)$ & $391(30.6)$ \\
College+ & $320(36.4)$ & $247(19.3)$ \\
Missing & $18(2.1)$ & $35(2.7)$ \\
Smoking habit, $\mathrm{n}(\%)$ & & \\
$\quad$ Never/former & $572(65.1)$ & $1146(89.7)$ \\
Current & $300(34.2)$ & $105(8.2)$ \\
Missing & $6(0.7)$ & $26(2.0)$ \\
Body mass index $\left(\mathrm{kg} / \mathrm{m}^{2}\right), \mathrm{n}(\%)$ & & \\
Less than 25 & $635(72.3)$ & $1060(83.0)$ \\
25 or more & $224(25.5)$ & $149(11.7)$ \\
Missing & $19(2.2)$ & $68(5.3)$ \\
Self-rated health & & $1047(82.0)$ \\
Better health & $730(83.1)$ & $230(18.0)$ \\
Poor health & $148(16.9)$ & \\
\hline
\end{tabular}

school (men/women) 17.0\%/13.5\%, high school 53.2\%/53.6\%, some college $6.1 \% / 21.8 \%$ and college $+22.4 \% / 10.7 \%$. Thus, our sample respondents were somewhat older than the typical Okayama resident and had a higher level of educational attainment.

Table 2 shows the distribution of the number of group involvement and poor health. Subjects involved in more groups

Table 2 The distribution of the number of group involvement and poor health stratified by sex

\begin{tabular}{|c|c|c|c|c|c|c|c|c|c|c|}
\hline & \multicolumn{5}{|l|}{ Men } & \multicolumn{5}{|c|}{ Women } \\
\hline & \multicolumn{2}{|c|}{ Total } & \multicolumn{3}{|c|}{ Poor health } & \multicolumn{2}{|c|}{ Total } & \multicolumn{3}{|c|}{ Poor health } \\
\hline & $\overline{\mathbf{N}}$ & $\%$ & $\overline{\mathbf{N}}$ & $\%$ & $\overline{\mathbf{P}_{\text {trend }}}$ & $\overline{\mathbf{N}}$ & $\%$ & $\overline{\mathbf{N}}$ & $\%$ & $\overline{P_{\text {trend }}}$ \\
\hline \multicolumn{11}{|c|}{ The number of total group involvement } \\
\hline 0 & 332 & 37.8 & 69 & 20.8 & & 485 & 38.0 & 114 & 23.5 & \\
\hline 1 & 213 & 24.3 & 34 & 16.0 & & 315 & 24.7 & 54 & 17.1 & \\
\hline 2 & 160 & 18.2 & 28 & 17.5 & & 238 & 18.6 & 32 & 13.4 & \\
\hline 3 & 93 & 10.6 & 9 & 9.7 & & 144 & 11.3 & 19 & 13.2 & \\
\hline 4 & 57 & 6.5 & 4 & 7.0 & & 54 & 4.2 & 6 & 11.1 & \\
\hline 5 & 18 & 2.1 & 3 & 16.7 & & 24 & 1.9 & 1 & 4.2 & \\
\hline 6 & 5 & 0.6 & 1 & 20.0 & $<0.01$ & 17 & 1.3 & 4 & 23.5 & $<0.01$ \\
\hline \multicolumn{11}{|c|}{ The number of bonding group involvement } \\
\hline 0 & 624 & 71.1 & 106 & 17.0 & & 905 & 70.9 & 173 & 19.1 & \\
\hline 1 & 175 & 19.9 & 32 & 18.3 & & 254 & 19.9 & 33 & 13.0 & \\
\hline 2 & 57 & 6.5 & 9 & 15.8 & & 82 & 6.4 & 14 & 17.1 & \\
\hline 3 & 18 & 2.1 & 1 & 5.6 & & 27 & 2.1 & 6 & 22.2 & \\
\hline 4 & 2 & 0.2 & 0 & 0.0 & & 4 & 0.3 & 2 & 50.0 & \\
\hline 5 & 0 & 0.0 & 0 & - & & 1 & 0.1 & 0 & 0.0 & \\
\hline 6 & 2 & 0.2 & 0 & 0.0 & 0.34 & 4 & 0.3 & 2 & 50.0 & 0.93 \\
\hline \multicolumn{11}{|c|}{ The number of bridging group involvement } \\
\hline 0 & 471 & 53.6 & 95 & 20.2 & & 672 & 52.6 & 150 & 22.3 & \\
\hline 1 & 190 & 21.6 & 25 & 13.2 & & 326 & 25.5 & 52 & 16.0 & \\
\hline 2 & 129 & 14.7 & 19 & 14.7 & & 166 & 13.0 & 19 & 11.4 & \\
\hline 3 & 54 & 6.2 & 4 & 7.4 & & 74 & 5.8 & 8 & 10.8 & \\
\hline 4 & 23 & 2.6 & 3 & 13.0 & & 23 & 1.8 & 1 & 4.3 & \\
\hline 5 & 10 & 1.1 & 2 & 20.0 & & 14 & 1.1 & 0 & 0.0 & \\
\hline 6 & 1 & 0.1 & 0 & 0.0 & 0.02 & 2 & 0.2 & 0 & 0.0 & $<0.01$ \\
\hline
\end{tabular}

were less likely to report poor health $(p<0.01)$ (except for women who participated in all six groups and men who participated in five or six groups, but the finding is based on only eight subjects). We observed a similar pattern with regard to bridging group involvement (men: $p=0.02$; women: $p<0.01$ ), but no clear trend was observed for bonding group involvement (men: $p=0.34$; women: $p=0.93$ ). There was no correlation between participation in bonding groups and participation in bridging groups (men: $r=-0.0151, p=0.65$; women: $r=0.0031$, $\mathrm{p}=0.91)$.

Table 3 shows the associations between each type of group involvement and poor health. Among men, no clear associations were found with regard to belonging to groups of both bonding and bridging variety. The sole exception was belonging to community associations where bonding variety was associated with a third the odds of poor health compared to individuals reporting zero involvement (OR $0.32,95 \%$ CI 0.13 to 0.77 ), while bridging variety was associated with roughly half the odds (OR 0.57 , 95\% CI 0.36 to 0.90). Among women, with the exception of PTA and citizens' group, each type of bridging group was associated with roughly half the odds of poor health compared to individuals reporting zero involvement. By contrast, no clear associations were found with regard to belonging to groups of the bonding variety.

Table 4 shows the gender-stratified associations between different levels of social capital and poor health. Among women, we found clear inverse associations between bridging social capital and poor health. However, among men, the relationships were either more attenuated or not statistically significant. Although no consistent associations were found with regard to bonding social capital in either gender, we found an apparent differential effect of bonding social capital between men and women; the ORs for poor health of those reporting the highest level of bonding social capital (compared to no social capital) were 0.20 and 0.93 among men and women, respectively.

Stratifying our analyses by age group yielded similar patterns to the overall sample among mid-aged and older ( $\geq 50$ years) individuals, although the associations were less clear among younger respondents. When we stratified by educational attainment, we also observed similar patterns as in the overall sample with the exception of the group with the lowest educational attainment among whom no clear associations were found (data available from the authors on request).

We further examined the associations between bonding and bridging social capital and poor health in a mutually exclusive manner (see additional appendix available online http://www. jech.com/supplemental).

\section{DISCUSSION}

The present study focused on distinguishing between bonding and bridging social capital and examined their differential relationships with self-rated health in Japan. Overall, while bridging social capital was inversely associated with poor health in both sexes, bonding social capital was not significantly associated. We found a differential pattern by sex, and women benefited more from bridging social capital than men whereas men may benefit more from bonding capital than women.

The conceptualisation of bonding versus bridging social capital is theoretically based on similarities in the characteristics of members of a group with respect to social status. ${ }^{1}{ }^{27}$ In US based research, the racial and ethnic diversity of a group has been viewed as most salient for bridging capital. However, the social cleavages that distinguish bonding from bridging social capital are likely to vary according to the societal context. For example, 
Table 3 ORs for poor health associated with each group involvement stratified by gender

\begin{tabular}{|c|c|c|c|c|}
\hline & \multicolumn{2}{|l|}{ Men } & \multicolumn{2}{|l|}{ Women } \\
\hline & $\begin{array}{l}\text { Crude } \\
\text { OR }(95 \% \mathrm{Cl})\end{array}$ & $\begin{array}{l}\text { Model 1* } \\
\text { OR (95\% CI) }\end{array}$ & $\begin{array}{l}\text { Crude } \\
\text { OR (95\% CI) }\end{array}$ & $\begin{array}{l}\text { Model 1* } \\
\text { OR (95\% CI) }\end{array}$ \\
\hline \multicolumn{5}{|c|}{ Parents and Teachers Association } \\
\hline No involvement & 1.00 & 1.00 & 1.00 & 1.00 \\
\hline Bonding social capital & $1.01(0.34$ to 3.01$)$ & $1.25(0.40$ to 3.92$)$ & 1.01 (0.54 to 1.88$)$ & 1.05 (0.50 to 2.23 ) \\
\hline Bridging social capital & $0.67(0.30$ to 1.51$)$ & 1.03 (0.44 to 2.39$)$ & $0.53(0.28$ to 1.00$)$ & 0.67 (0.32 to 1.39$)$ \\
\hline \multicolumn{5}{|l|}{ Sports club } \\
\hline No involvement & 1.00 & 1.00 & 1.00 & 1.00 \\
\hline Bonding social capital & 1.02 (0.58 to 1.78$)$ & 1.14 (0.62 to 2.08$)$ & $0.69(0.43$ to 1.12$)$ & $0.59(0.34$ to 1.01$)$ \\
\hline Bridging social capital & $0.82(0.51$ to 1.31$)$ & $1.00(0.61$ to 1.64$)$ & 0.35 (0.22 to 0.54$)$ & 0.38 (0.23 to 0.62$)$ \\
\hline \multicolumn{5}{|l|}{ Alumni association } \\
\hline No involvement & 1.00 & 1.00 & 1.00 & 1.00 \\
\hline Bonding social capital & $0.89(0.53$ to 1.49$)$ & $0.93(0.53$ to 1.64$)$ & 0.88 (0.56 to 1.39$)$ & 0.81 (0.49 to 1.35$)$ \\
\hline Bridging social capital & $0.58(0.34$ to 1.01$)$ & 0.67 (0.38 to 1.18$)$ & 0.50 (0.28 to 0.88$)$ & $0.43(0.22$ to 0.81$)$ \\
\hline \multicolumn{5}{|l|}{ Political campaign club } \\
\hline No involvement & 1.00 & 1.00 & 1.00 & 1.00 \\
\hline Bonding social capital & $0.58(0.17$ to 1.97$)$ & $0.46(0.13$ to 1.57$)$ & $1.60(0.57$ to 4.48$)$ & $1.23(0.42$ to 3.61$)$ \\
\hline Bridging social capital & $0.54(0.25$ to 1.15$)$ & $0.52(0.24$ to 1.12$)$ & $0.54(0.24$ to 1.20$)$ & $0.37(0.15$ to 0.96$)$ \\
\hline \multicolumn{5}{|l|}{ Citizens' group } \\
\hline No involvement & 1.00 & 1.00 & 1.00 & 1.00 \\
\hline Bonding social capital & $0.50(0.11$ to 2.17$)$ & $0.40(0.09$ to 1.78$)$ & 1.10 (0.56 to 2.17 ) & 0.98 (0.47 to 2.04$)$ \\
\hline Bridging social capital & $0.59(0.28$ to 1.26$)$ & $0.58(0.26$ to 1.25$)$ & 0.69 (0.40 to 1.19$)$ & 0.60 (0.32 to 1.12$)$ \\
\hline \multicolumn{5}{|l|}{ Community association } \\
\hline No involvement & 1.00 & 1.00 & 1.00 & 1.00 \\
\hline Bonding social capital & 0.42 (0.19 to 0.94$)$ & 0.32 (0.13 to 0.77$)$ & 0.98 (0.60 to 1.59 ) & 0.68 (0.39 to 1.18 ) \\
\hline Bridging social capital & $0.64(0.42$ to 0.98$)$ & $0.57(0.36$ to 0.90$)$ & $0.59(0.42$ to 0.85$)$ & 0.51 (0.34 to 0.76$)$ \\
\hline
\end{tabular}

*Adjusted for age, living arrangement, educational attainment, smoking habit and overweight.

in predicting the outbreak of sectarian violence across cities of India, Varshney defined bridging social capital according to whether civic organisations brought together the two main religious groups-Hindu and Muslim residents-within a locality. ${ }^{32}$ According to Varshney's study, cities that were successful in maintaining peace were characterised by the presence of bridging capital in which both Hindus and Muslims were active members. The presence of such groups proved to be instrumental in quelling rumours and other triggers of outbreaks of violence.

Our study did not find evidence of a consistent beneficial effect of bonding social capital on poor health, which contradicts with previous findings from Western countries. ${ }^{20} 21$ This observation may reflect the 'downsides' of social capital in Japanese society. Indeed, social capital can be a double-edged sword, which is not health-promoting in every instance. As an example of a highly cohesive society, many aspects of Japanese society exemplify the downsides of social capital that is 'too strong' and veers in the direction of burdening members with excessive obligations and duties. ${ }^{33}$ In high homogeneous society the accessibility to heterogeneous resources may be more advantageous, while in high heterogeneous society the benefit could be attenuated. Our findings that PTA membership was not associated with health benefits in either gender and that women benefited more from bridging social capital are consistent with this hypothesis. In Japan, parents-usually womenare routinely assigned to serve as members of their children's PTA and the 'obligatory' nature of this participation may counteract the benefits of social capital. Due to patriarchy, women have also tended to be excluded from bridging types of social positions, which may account for the greater benefit of bridging social capital for them when they do get to connect to such groups. Thus, any strategy to 'capitalise' on social capital in
Japanese society should pay careful heed to the specific types that are likely to enhance the well-being of participants. For example, we found that community associations-in both the bonding and bridging forms - were associated with good health in men. Indeed, such groups in Japan ('chounaikai') are likely to be long-standing, voluntary, community based associations that promote the daily exchange of social support among residents. ${ }^{34}$

As alternative explanations of the inconsistent findings, the different definition of bonding and bridging social capital should be noted. In Japanese society, which is characterised by comparative racial and ethnic homogeneity, the social cleavages that define 'bridging' social capital look very different from other societies. Post World War II Japanese society has also been characterised by the growth of a broad middle class (embourgeoisement) where class distinctions have been less pronounced compared to other societies. In such a context, social cleavages are more likely to exist along other dimensions such as gender and generational differences. Our survey respondents were also more educated compared to the Okayama prefecture population; thereby, limiting the generalisability of our findings. Access to bridging social capital is theorised to be particularly important for disadvantaged individuals in terms of enabling them access to resources held by others in higher socioeconomic positions. ${ }^{26}$ Thus, our findings may have underestimated the effects of bridging social capital for the general population. Further, the discrepancy could be also due to insufficient statistical power of the present study.

A limitation of our study is that our survey did not specify the dimension along which groups were diverse-gender, occupation or generation. Diversity in each (or all) of these dimensions could be theoretically linked to health outcomes. For example, occupational heterogeneity within a group can provide members from lower class occupations with access to valued 
Table 4 ORs for poor health associated with social capital stratified by gender

\begin{tabular}{|c|c|c|c|c|}
\hline & $\begin{array}{l}\text { Poor health } \\
\text { N (\%) }\end{array}$ & $\begin{array}{l}\text { Crude } \\
\text { OR }(95 \% \text { CI) }\end{array}$ & $\begin{array}{l}\text { Model 1* } \\
\text { OR }(95 \% \mathrm{CI})\end{array}$ & $\begin{array}{l}\text { Model } 2 \dagger \\
\text { OR }(95 \% \text { CI) }\end{array}$ \\
\hline \multicolumn{5}{|l|}{ Men } \\
\hline \multicolumn{5}{|c|}{ Social capital } \\
\hline None & $69(20.8)$ & 1.00 & 1.00 & \\
\hline Low & $34(16.0)$ & $0.72(0.46$ to 1.14$)$ & 0.74 (0.46 to 1.21$)$ & \\
\hline Middle & $28(17.5)$ & $0.81(0.50$ to 1.32$)$ & 0.91 (0.54 to 1.53 ) & \\
\hline High & $17(16.9)$ & $0.42(0.24$ to 0.73$)$ & 0.41 (0.23 to 0.75$)$ & \\
\hline \multicolumn{5}{|c|}{ Bonding social capital } \\
\hline None & $106(17.0)$ & 1.00 & 1.00 & 1.00 \\
\hline Low & $32(18.3)$ & $1.09(0.71$ to 1.69$)$ & $1.14(0.71$ to 1.81$)$ & $1.15(0.72$ to 1.84$)$ \\
\hline Middle & $9(15.8)$ & $0.92(0.44$ to 1.92$)$ & 0.87 (0.40 to 1.89$)$ & $0.86(0.40$ to 1.86$)$ \\
\hline High & $1(4.6)$ & $0.23(0.03$ to 1.75$)$ & 0.21 (0.03 to 1.60$)$ & $0.20(0.25$ to 1.51$)$ \\
\hline \multicolumn{5}{|c|}{ Bridging social capital } \\
\hline None & $95(20.2)$ & 1.00 & 1.00 & 1.00 \\
\hline Low & 25 (13.2) & $0.60(0.37$ to 0.97$)$ & $0.71(0.43$ to 1.16$)$ & $0.72(0.44$ to 1.18$)$ \\
\hline Middle & $19(14.7)$ & $0.68(0.40$ to 1.17$)$ & 0.76 (0.43 to 1.34 ) & $0.74(0.42$ to 1.30$)$ \\
\hline High & $9(10.2)$ & $0.45(0.22$ to 0.93$)$ & $0.49(0.23$ to 1.04$)$ & $0.47(0.22$ to 0.99$)$ \\
\hline \multicolumn{5}{|l|}{ Women } \\
\hline \multicolumn{5}{|c|}{ Social capital } \\
\hline None & $114(23.5)$ & 1.00 & 1.00 & \\
\hline Low & $54(17.1)$ & $0.67(0.47$ to 0.97$)$ & 0.66 (0.44 to 0.98$)$ & \\
\hline Middle & $32(13.5)$ & $0.51(0.33$ to 0.78$)$ & 0.51 (0.32 to 0.83 ) & \\
\hline High & $30(12.6)$ & 0.47 (0.30 to 0.72$)$ & $0.33(0.20$ to 0.56$)$ & \\
\hline \multicolumn{5}{|c|}{ Bonding social capital } \\
\hline None & $173(19.1)$ & 1.00 & 1.00 & 1.00 \\
\hline Low & $33(13.0)$ & $0.63(0.42$ to 0.94$)$ & 0.61 (0.39 to 0.94 ) & $0.62(0.40$ to 0.97$)$ \\
\hline Middle & $14(17.1)$ & $0.87(0.48$ to 1.59$)$ & 0.84 (0.43 to 1.63 ) & $0.78(0.40$ to 1.53$)$ \\
\hline High & $10(27.8)$ & 1.63 (0.77 to 3.44$)$ & 0.93 (0.39 to 2.22 ) & $0.93(0.39$ to 2.20$)$ \\
\hline \multicolumn{5}{|c|}{ Bridging social capital } \\
\hline None & $150(22.3)$ & 1.00 & 1.00 & 1.00 \\
\hline Low & $52(16.0)$ & $0.66(0.47$ to 0.94$)$ & 0.70 (0.48 to 1.02 ) & 0.72 (0.49 to 1.05$)$ \\
\hline Middle & 19 (11.5) & $0.45(0.27$ to 0.75$)$ & 0.48 (0.27 to 0.84$)$ & $0.49(0.28$ to 0.87$)$ \\
\hline High & $9(8.0)$ & $0.30(0.15$ to 0.61$)$ & 0.25 (0.11 to 0.55$)$ & $0.24(0.11$ to 0.54$)$ \\
\hline
\end{tabular}

*Adjusted for age, living arrangement, educational attainment, smoking habit and overweight.

†Adjusted for age, living arrangement, educational attainment, smoking habit, overweight and bridging social capital in bonding social capital model. Adjusted for age, living arrangement, educational attainment, smoking habit, overweight and bonding social capital in bridging social capital model.

None: no group involvement; low: one group; middle: two groups; high: three or more groups.

resources-for example, job referrals. Intergenerational diversity within a group could similarly provide younger members with mentoring and access to life opportunities, especially in a society like Japan that places a high premium on seniority. Finally, gender heterogeneity could be important for expanding opportunities for women, especially in a patriarchal society such as Japan. Our finding that women benefited more from bridging capital (whereas men benefited more from bonding capital) is consistent with such an interpretation. Further research is needed to distinguish between these alternative hypotheses.

Additional limitations of the study should be noted. First, due to the cross-sectional design, we cannot exclude the possibility of reverse causation in which healthier people tend to participate in many groups. However, the differential effect estimates of bonding versus bridging social capital on health cannot be fully explained by the reverse causation. In other words, if reverse causation is the sole explanation of our findings, it would be expected to apply to both bonding and bridging social capital in a similar manner. Second, our findings depended on self-rated health and social capital information obtained through the same questionnaire. Thus, we cannot exclude common method bias and this may have resulted in bias away from the null. Again, the

\section{What is already known about this subject?}

- Few studies have distinguished between the effects of bonding versus bridging social capital on health outcomes.

- Previous studies have operationalised bonding and bridging social capital along the dimension of race/ethnicity.

\section{What does this study add?}

- Bridging social capital (measured along the dimensions of gender, age and occupation) was associated with better selfrated health in both sexes, whereas the association was less consistent with regard to bonding social capital.

- Japanese women benefited more from involvement in bridging social capital, whereas men may benefit more from bonding social capital. 
differential findings for bonding versus bringing social capital suggest that this is less likely. Finally, if people in a poor state of health were both less likely to participate in groups and less likely to respond to the survey, this would also bias the results away from the null due to selection bias.

In conclusion, the present study suggests differential associations of bonding and bridging social capital on health and provides empirical evidence for protective effects of bridging social capital on individual health among Japanese residents. In addition, it is suggested that bonding social capital does not necessarily produce adverse health effects in Japan at least in non-deprived neighbourhoods. This study underscores the significance of measuring bonding and bridging social capital separately in future studies that evaluate the relationship between social capital and health.

Acknowledgements We gratefully acknowledge the invaluable assistance of Hiroaki Matsuoka, Katsumi Nakase, Toshiaki Noriyasu and SV Subramanian for the present study. We are also grateful to the study participants for their involvement in the research.

\section{Competing interests None declared}

Ethics approval This study was conducted with the approval of the Harvard School of Public Health.

Provenance and peer review Not commissioned; externally peer reviewed.

\section{REFERENCES}

1. Kawachi I. Commentary: social capital and health: making the connections one step at a time. Int J Epidemiol 2006;35:989-93.

2. Veenstra G. Social capital, SES and health: an individual-level analysis. Soc Sci Med 2000;50:619-29.

3. Hyyppä MT, Mäki J. Individual-level relationships between social capital and self-rated health in a bilingual community. Prev Med 2001:32:148-55.

4. Hyyppä MT, Mäki J. Social participation and health in a community rich in stock of social capital. Health Educ Res 2003;18:770-9.

5. Drukker M, Kaplan C, Feron F, et al. Children's health-related quality of life, neighbourhood socio-economic deprivation and social capital. A contextual analysis. Soc Sci Med 2003;57:825-41.

6. Harpham T, Grant E, Rodriguez C. Mental health and social capital in Cali, Colombia. Soc Sci Med 2004;58:2267-77.

7. Fujisawa Y, Hamano T, Takegawa S. Social capital and perceived health in Japan: an ecological and multilevel analysis. Soc Sci Med 2009;69:500-5.

8. Ichida $\mathbf{Y}$, Kondo $\mathrm{K}$, Hirai $\mathrm{H}$, et al. Social capital, income inequality and self-rated health in Chita peninsula, Japan: a multilevel analysis of older people in 25 communities. Soc Sci Med 2009;69:489-99.

9. Aida J, Hanibuchi T, Nakade M, et al. The different effects of vertical social capital and horizontal social capital on dental status: a multilevel analysis. Soc Sci Med 2009;69:512-18.

10. Suzuki E, Takao S, Subramanian SV, et al. Does low workplace social capital have detrimental effect on workers' health? Soc Sci Med 2010;70:1367-72.

11. Pearce J, Witten K, Hiscock R, et al. Are socially disadvantaged neighbourhoods deprived of health-related community resources? Int J Epidemiol 2007:36:348-55.
12. Blakely T, Atkinson J, Ivory V, et al. No association of neighbourhood volunteerism with mortality in New Zealand: a national multilevel cohort study. Int J Epidemiol 2006;35:981-9.

13. Veenstra G. Social capital and health (plus wealth, income inequality and regional health governance). Soc Sci Med 2002;54:849-68.

14. Turrell G, Kavanagh A, Subramanian SV. Area variation in mortality in Tasmania (Australia): the contributions of socioeconomic disadvantage, social capital and geographic remoteness. Health Place 2006;12:291-305.

15. Islam MK, Gerdtham UG, Gullberg B, et al. Social capital externalities and mortality in Sweden. Econ Hum Biol 2008;6:19-42.

16. Gittel R, Videl R. Community Organizing: Building Social Capital as a Development Strategy. Thousand Oaks: Sage Publications, 1998.

17. Szreter S, Woolcock M. Health by association? Social capital, social theory, and the political economy of public health. Int J Epidemiol 2004; 33:650-67.

18. Davey Smith G, Lynch J. Commentary: social capital, social epidemiology and disease aetiology. Int J Epidemiol 2004;33:691-700; discussion 5-9.

19. Mitchell CU, LaGory M. Social capital and mental distress in an impoverished community. City \& Community 2002;1:199-222.

20. Beaudoin CE. Bonding and bridging neighborliness: an individual-level study in the context of health. Soc Sci Med 2009;68:2129-36.

21. Kim D, Subramanian SV, Kawachi I. Bonding versus bridging social capital and their associations with self rated health: a multilevel analysis of 40 US communities. J Epidemiol Community Health 2006;60:116-22.

22. Press release from Ministry of Justice. http://www.moj.go.jp/nyuukokukanri/kouhou/ press 090710-1 090710-1.html (accessed 7 Apr 2010).

23. Islam MK, Merlo J, Kawachi I, et al. Social capital and health: does egalitarianism matter? A literature review. Int J Equity Health 2006;5:3. http://www.equityhealthj. com/content/5/1/3/.

24. Caughy MO, O'Campo PJ, Muntaner C. When being alone might be better: neighborhood poverty, social capital, and child mental health. Soc Sci Med 2003; 57:227-37

25. Ziersch AM, Baum FE. Involvement in civil society groups: is it good for your health? J Epidemiol Community Health 2004;58:493-500.

26. Lin N. Social Capital: A Theory of Social Structure and Action. New York: Cambridge University Press, 2001.

27. Kawachi I, Subramanian SV, Kim D, eds. Social Capital and Health. New York: Springer, 2008.

28. Harpham T, Grant E, Thomas E. Measuring social capital within health surveys: key issues. Health Policy Plan 2002;17:106-11.

29. Idler EL, Benyamini Y. Self-rated health and mortality: a review of twenty-seven community studies. J Health Soc Behav 1997;38:21-37.

30. Press release from the City Government of Okayama. The age distribution by sex from the Basic Resident Registration, the statistical report of the City Government of Okayama in 2009. http://www.city.okayama.jp/soumu/toukei/nenpou/data h21/ 006 00.xls (accessed 27 0ct 2010).

31. Press release from Department of Statistics, Ministry of Internal Affairs and Communication. Employed persons 15 years of age and over, by school attendance and type of last school completed (6 groups), occupation (major groups), age (five-year groups) and sex: okayama prefecture. 2000. http://www.e-stat.go.jp/SG1/ estat/GL08020103.do?_xlsDownload_\&fileld $=0000000344$ FCgreleaseCount $=2$ (accessed 27 Oct 2010).

32. Varshney A. Ethnic Conflict and Civic Life. Hindus and Muslims in India. New Haven: Yale University Press, 2002.

33. Takao S. Research on social capital and health in Japan. A commentary on Ichida and on Fujisawa. Soc Sci Med 2009:69:509-11.

34. Chounaikai. <http://ja.wikipedia.org/wiki/\%E7\%94\%BA\%E5\%86\%85\%E4\%BC\%9A> (accessed 7 Apr 2010). 